\title{
Association of circulating omentin-1 level with arterial stiffness and carotid plaque in type 2 diabetes
}

Hye Jin Yoo ${ }^{1}$, Soon Young Hwang ${ }^{2}$, Ho Cheol Hong ${ }^{1}$, Hae Yoon Choi ${ }^{1}$, Sae Jeong Yang ${ }^{1}$, Ji A Seo ${ }^{1}$, Sin Gon Kim', Nan Hee Kim ${ }^{1}$, Kyung Mook Choi ${ }^{1}$, Dong Seop Choi ${ }^{1}$ and Sei Hyun Baik ${ }^{1 *}$

\begin{abstract}
Background: Adipokines contribute directly to the atherosclerotic process, connecting metabolic disorders such as obesity and diabetes to cardiovascular disease. Omentin-1 is a recently discovered novel adipokine, so data about the relationship of this adipokine to vascular health in type 2 diabetes is limited.

Methods: We enrolled 60 people with type 2 diabetes, with or without carotid plaque, and 30 participants with normal glucose tolerance. We measured serum omentin-1, high-sensitivity C-reactive protein (hsCRP) levels, and the homeostasis model assessment of insulin resistance (HOMA-IR), as well as other cardiovascular risk factors. Vascular health was assessed by brachial ankle pulse wave velocity (baPWV) and carotid intima-media thickness (IMT).

Results: Serum omentin-1 levels were significantly decreased in type 2 diabetes patients compared to normal glucose controls and was further reduced in type 2 diabetes patients with carotid plaque compared to those without carotid plaque. Multiple stepwise regression analysis showed that age, systolic blood pressure, history of use of statins, angiotensin receptor blockers or angiotensin-converting enzyme inhibitors, and serum omentin-1 level were independent factors determining baPWV in people with type 2 diabetes $\left(r^{2}=0.637\right)$. Furthermore, in multivariate logistic regression analysis, circulating omentin-1 level was an independent decisive factor for the presence of carotid plaque in type 2 diabetes patients, even after adjusting for age, gender, body mass index, systolic blood pressure, fasting blood glucose, low density lipoprotein cholesterol, and history of smoking and medication (odds ratio, 0.621; 95\% confidence interval, 0.420-0.919; $P=0.017$ ).
\end{abstract}

Conclusions: Circulating omentin-1 level was independently correlated with arterial stiffness and carotid plaque in type 2 diabetes, even after adjusting for other cardiovascular risk factors and detailed medication history.

Keywords: omentin-1, pulse wave velocity, carotid intima media thickness, type 2 diabetes

\section{Background}

The prevalence of diabetes is expected to rapidly increase from 171 million individuals ( $2.8 \%$ of the world's population) in 2000 to 366 million (4.4\% of the world's population) by 2030 [1]. Individuals with diabetes have two- to three-fold increased risk of myocardial infarction or stroke compared to individuals without diabetes [2]. However, the underlying mechanisms linking type 2 diabetes with cardiovascular disease remain poorly understood. Recent

\footnotetext{
* Correspondence: 103hyun@korea.ac.kr

'Division of Endocrinology and Metabolism, Department of Internal

Medicine, Korea University College of Medicine, Seoul, Korea

Full list of author information is available at the end of the article
}

evidence has shown that some adipokines are major regulators of insulin resistance and direct mediators of endothelial dysfunction and macrophage infiltration of vessel walls [3]. The identification of a novel adipokine involved in the atherosclerotic process might provide new opportunities for preventing cardiovascular disease in patients with type 2 diabetes.

Omentin is a novel fat depot-specific adipokine that was identified in 2003 from a visceral omental adipose tissue cDNA library [4]. The omentin gene is located in the 1q22-q23 chromosomal region, which has been linked to type 2 diabetes in several populations [5,6], suggesting that omentin may be a candidate gene for type 2 diabetes 
susceptibility in humans. In fact, Yang et al. [7] demonstrated that recombinant omentin-1 enhances insulinstimulated glucose uptake and Akt phosphorylation in human adipocytes. Several clinical studies have shown that the serum omentin-1 level is significantly decreased in obese patients or patients with polycystic ovary syndrome or diabetes [8-10]. In addition, circulating omentin-1 levels are negatively correlated with metabolic risk factors, including body mass index, waist circumference, and insulin resistance [8-10].

Recent clinical studies have focused on the influence of the novel adipokine omentin-1 on vascular health [11-14]. In these studies, circulating omentin-1 had a negative correlation with atherosclerotic parameters. However, no previous studies have clarified the relationship of serum omentin- 1 with atherosclerosis in subjects with type 2 diabetes. Carotid intima-media thickness (IMT) and arterial stiffness are useful surrogate markers for subclinical atherosclerosis and are significantly correlated with various metabolic risk factors $[15,16]$. In prospective studies, both arterial stiffness and carotid IMT have proven to be consistent and independent predictors for cardiovascular events [17]. Recently, Dall Pozza et al. [18] showed that longitudinal carotid IMT is indicative of disease progression during a four year period, even in adolescents with type 1 diabetes, and that brachial ankle pulse wave velocity (baPWV) is a non-invasive method for quickly measuring arterial stiffness that is not influenced by operator technique [19].

Therefore, in this study, we determined the relationship of circulating omentin-1 levels with atherosclerosis, as measured by carotid IMT and baPWV, in subjects with type 2 diabetes and controls. Furthermore, to determine the exact correlation of circulating level of omentin-1 with baPWV and carotid IMT in type 2 diabetes, we adjusted for other cardiovascular risk factors and detailed drug history that could affect vascular function.

\section{Methods}

\section{Study design and participants}

The study subjects were 30 people with type 2 diabetes without carotid plaque, 30 people with type 2 diabetes with carotid plaque, and 30 control participants with normal glucose tolerance. Diabetes was defined as a fasting plasma glucose value $\geq 7.0 \mathrm{mmol} / \mathrm{L}(126 \mathrm{mg} / \mathrm{dL})$ or a previous diagnosis of diabetes. All were self-referred from the Department of Endocrinology and Metabolism at Korea University Guro Hospital. All subjects in the control group were administered a 75-g oral glucose loading test to exclude subjects with pre-diabetes or undiagnosed diabetes using the criteria of the American Diabetes Association [20]. The study exclusion criteria included histories of cardiovascular diseases (myocardial infarction, unstable angina, stroke, peripheral artery disease, or cardiovascular revascularization), stage 2 hypertension (resting blood pressure $\geq 160 / 100 \mathrm{mmHg}$ ), uncontrolled diabetes mellitus (HaA1c > 10\%), malignancy, or severe renal or hepatic disease. We also excluded patients with inflammatory conditions such as vasculitis or aortitis, or acute infectious disease. We investigated smoking and medication histories including use of insulin, oral hypoglycemic agents, statins, anti-platelet agents, angiotensin receptor blocker (ARB), angiotensin-converting enzyme (ACE) inhibitors or calcium channel blockers. All participants provided written informed consent, and the Korea University Institutional Review Board, in accordance with the Declaration of Helsinki of the World Medical Association, approved the study protocol.

\section{Clinical and laboratory measurements}

Body mass index (BMI) was calculated as weight $/$ height $^{2}$ $\left(\mathrm{kg} / \mathrm{m}^{2}\right)$ and waist circumference was measured at the midpoint between the lower border of the rib cage and the iliac crest. All blood samples were obtained the morning after a 12-hour overnight fast, and were immediately stored at $-80^{\circ} \mathrm{C}$. Serum triglycerides and high-density lipoprotein-cholesterol (HDL-C) were determined enzymatically using a chemical analyzer (Hitachi 747; Hitachi Inc., Tokyo, Japan). Low-density lipoprotein (LDL)-cholesterol concentration was estimated using the Friedewald formula [21]. The glucose oxidase method was used to measure plasma glucose and an electrochemiluminescence immunoassay (Roche Diagnostics, Indianapolis, IN, USA) was used to measure insulin levels. Insulin resistance was calculated by the homeostasis model assessment of insulin resistance (HOMA-IR). hsCRP levels were measured by latex-enhanced turbidimetric immunoassay (HiSens hsCRP LTIA, HBI Co., Ltd.), with an interassay coefficient of variation of $7.2 \%$. Serum concentrations of omentin-1 were determined by an enzyme-linked immunosorbent assay (ELISA) kit (Apotech, Axxora, Nottingham, UK); intra- and interassay variations were $3.6 \pm 0.7 \%$ and $4.6 \pm 0.3 \%$, respectively.

\section{Measurement of baPWV}

After subjects rested in the supine position for $5 \mathrm{~min}$ utes, baPWV was measured using a volume-plethysmographic apparatus (model BP-203RPE II; Colin, Komaki, Japan) that simultaneously recorded baPWV and brachial and ankle blood pressures on the left and right sides. The details of this method, including validity and reproducibility, were described previously by Yamashina et al. [22]. The intra- and inter-observer reproducibility of this method in the present study were $10.0 \%$ and $8.4 \%$, respectively. The baPWV was calculated as the mean of the left and right baPWV values. 


\section{Measurement of carotid IMT}

The IMT of the common carotid artery was determined using high-resolution B-mode ultrasonography (EnVisor; Philips Medical Systems, Andover, MA, USA) with a 5$12 \mathrm{MHz}$ transducer. Carotid plaque was defined as a focal structure protruding into the arterial lumen with a thickness $\geq 1.3 \mathrm{~mm}$ [23]. Measurements of the carotid IMT were made using IMT measurement software (Intimascope; Media Cross Co., Tokyo, Japan) at three levels of the lateral and medial walls of the carotid artery, 1-3 $\mathrm{cm}$ proximal to the carotid bifurcation. The maximal IMT was the value at the maximal point of the region. Carotid IMT was calculated as the mean of the maximal left and right IMT values. All measurements were recorded by a single trained technician who was blinded to the anthropometric and laboratory data.

\section{Statistical analysis}

Each variable was examined for normal distribution by the Kolmogorov-Smirnov equality of distributions test. Data are expressed as the mean with standard deviations (SDs) or median (interquartile range, $25 \%-75 \%$ ), or as a percentage. Differences among the groups were tested using ANOVA for normally distributed variables or the KruskalWallis $\mathrm{H}$ test for non-normally distributed variables, and Fisher's exact test or Pearson's chi-square test for categorical variables. Subsequent pair-wise comparisons were performed by Tukey's HSD post hoc analysis or the Wilcoxon rank-sum test. Analysis of covariance (ANCOVA) was used to compare the mean baPWV values according to tertile of serum omentin-1 level after adjusting for known covariates. Multiple linear stepwise regression analysis with baPWV as a dependent variable was performed to identify the risk factors that determined baPWV in type 2 diabetes. Subsequently, age, gender, BMI, systolic blood pressure, fasting blood glucose, smoking and medication history, including usage of statins and ARB or ACE-inhibitors, and circulating omentin-1 level, were used as independents variables. Unadjusted and adjusted odds ratios (ORs) with 95\% confidence intervals (CIs) predicting carotid plaque in type 2 diabetes patients based on circulating omentin-1 level were generated using univariate and multivariate logistic regression analyses after controlling for other potential covariates. All statistical results were based on 2sided tests. Data were analyzed using SPSS for Windows (version 12.0; SPSS Inc., Chicago, IL, USA). We regarded a $P$ value of less than 0.05 as statistically meaningful.

\section{Results}

\section{Characteristics of study subjects}

The clinical and biochemical characteristics of the study subjects are in Table 1. Although there were no significant differences in age, gender or BMI, significant differences between groups were seen in waist circumference, systolic blood pressure, fasting blood glucose, HOMA-IR, and history of medication use including statins, antihypertensive agents, and anti-platelet agents (Table 1). In particular, baPWV values showed an increasing trend in subjects with normal glucose tolerance, those with type 2 diabetes without plaque and those with type 2 diabetes with plaque. In addition, circulating omentin-1 levels were significantly decreased in type 2 diabetes patients compared to normal glucose controls and were further reduced in type 2 diabetes patients with carotid plaque compared to those without carotid plaque (Figure 1).

\section{Arterial stiffness stratified by the tertile of serum omentin-1 level in type 2 diabetes}

Subjects with the highest tertile serum levels of omentin-1 (T3) exhibited the most significant detrimental signs of baPWV compared to those in tertile serum omentin-1 groups T2 or T1 after adjusting for age, gender, and BMI (Figure 2, Model 1). Further, after adjusting for other confounding factors such as systolic blood pressure, smoking, and drug history (i.e., usage of statins or ARB or ACE inhibitors), arterial stiffness was significantly associated with increased level of serum omentin-1 ( $P$ for trends $=0.023$; Figure 2, Model 2). Based on the results of multiple linear regression analyses, age $(P<0.001)$, systolic blood pressure $(P<0.001)$, medication history including statin $(P=0.007)$ and ARB or ACE inhibitor $(P=0.013)$ and serum omentin-1 level $(P=0.023)$ were independent determining factors for mean baPWV $\left(R^{2}=0.637\right)$

\section{Odds ratio of serum omentin-1 level predicting carotid plaque in type 2 diabetes}

According to univariate and multivariate logistic regression analyses, the ORs of carotid plaque according to serum omentin-1 level are displayed in Table 2. Interestingly, the OR for carotid plaque was 0.692 (95\% CI, 0.510-0.938) according to the increased level of serum omentin-1 based on an unadjusted model. The adjusted ORs for carotid plaques in the first, second, third and fourth models were 0.672 (95\% CI, 0.478 0.944), 0.650 (95\% CI, 0.454 0.930), 0.649 (95\% CI, 0.438 0.962), 0.621 (95\% CI, 0.420 0.919), respectively. Most importantly, inclusion of confounding factors which can affect carotid atherosclerosis did not alter the results of our multiple regression analyses.

\section{Discussion}

We demonstrated that serum omentin-1 levels were significantly decreased in type 2 diabetes patients compared to normal glucose controls, and were further reduced in type 2 diabetes patients with carotid plaque compared to those without carotid plaque. Furthermore, the circulating omentin-1 value was an independent determining factor for arterial stiffness and the existence 
Table 1 Baseline characteristics of study subjects

\begin{tabular}{|c|c|c|c|c|c|c|c|}
\hline \multirow[b]{2}{*}{ Age (years) } & $(\mathrm{N}=30$ & se tolerance & \multicolumn{2}{|c|}{$\begin{array}{l}\text { Type } 2 \text { diabetes } \\
\text { without carotid plaque } \\
(\mathrm{N}=30)\end{array}$} & \multicolumn{2}{|c|}{$\begin{array}{l}\text { Type } 2 \text { diabetes } \\
\text { with carotid plaque } \\
(\mathrm{N}=30)\end{array}$} & $P$-value \\
\hline & 54.07 & \pm 8.14 & 53.1 & \pm 6.81 & 56.47 & \pm 6.04 & 0.169 \\
\hline Gender (M:F) & 12 & $: 18$ & 10 & $: 20$ & 15 & $: 15$ & 0.418 \\
\hline $\mathrm{BMI}\left(\mathrm{kg} / \mathrm{m}^{2}\right)$ & 23.99 & \pm 2.88 & 23.89 & \pm 2.29 & 24.18 & \pm 2.11 & 0.895 \\
\hline Waist circumference (cm) & 85.19 & $\pm 6.05^{\mathrm{a}}$ & 93.68 & $\pm 6.76^{\mathrm{b}}$ & 95.12 & $\pm 3.98^{b}$ & $<0.001$ \\
\hline $\mathrm{SBP}(\mathrm{mmHg})$ & 119.67 & $\pm 12.73^{a}$ & 119.33 & $\pm 10.56^{a}$ & 129.83 & $\pm 17.95^{b}$ & 0.007 \\
\hline $\mathrm{DBP}(\mathrm{mmHg})$ & 77.67 & \pm 10.06 & 74.5 & \pm 8.55 & 77.72 & \pm 9.92 & 0.332 \\
\hline Fasting blood glucose (mmol/L) & 5.16 & $\pm 0.55^{\mathrm{a}}$ & 7.06 & $\pm 2.06^{b}$ & 7.28 & $\pm 1.53^{b}$ & $<0.001$ \\
\hline HOMA_IR & 1.66 & $(0.92,2.52)^{\mathrm{a}}$ & 2.7 & $(1.91,4.10)^{b}$ & 2.96 & $(1.92,3.86)^{b}$ & 0.002 \\
\hline $\mathrm{HbA} 1 \mathrm{c}$ & 5.68 & $\pm 0.34^{\mathrm{a}}$ & 7.27 & $\pm 1.04^{b}$ & 7.4 & $\pm 0.94^{b}$ & $<0.001$ \\
\hline LDL cholesterol (mmol/L) & 2.58 & \pm 0.81 & 2.28 & \pm 0.60 & 2.27 & \pm 0.50 & 0.122 \\
\hline HDL cholesterol (mmol/L) & 1.41 & \pm 0.39 & 1.24 & \pm 0.34 & 1.29 & \pm 0.27 & 0.159 \\
\hline Triglyceride (mmol/L) & 1.02 & $(0.70,1.56)$ & 1.17 & $(0.98,2.29)$ & 1.36 & $(1.02,1.68)$ & 0.057 \\
\hline hsCRP (mg/dL) & 0.56 & $(0.34,1.45)$ & 0.57 & $(0.35,1.21)$ & 0.45 & $(0.30,1.13)$ & 0.428 \\
\hline Carotid IMT (cm) & 0.84 & $\pm 0.11^{\mathrm{a}}$ & 0.86 & $\pm 0.12^{a}$ & 0.98 & $\pm 0.16^{b}$ & $<0.001$ \\
\hline baPWV (m/sec) & 13.26 & $\pm 1.77^{\mathrm{a}}$ & 14.29 & $\pm 2.57^{\mathrm{a}}$ & 16.22 & $\pm 3.07^{b}$ & $<0.001$ \\
\hline Current smoker (\%) & 26.77 & & 30 & & 46.67 & & 0.218 \\
\hline Statin (\%) & $10.00^{\mathrm{a}}$ & & $33.33^{\mathrm{at}}$ & & $40.44^{b}$ & & 0.024 \\
\hline Anti-platelet agent (\%) & 6.67 & & 6.67 & & 26.67 & & 0.031 \\
\hline ARB or ACE inhibitor (\%) & $10.00^{\mathrm{a}}$ & & $16.67^{\mathrm{at}}$ & & $40.00^{b}$ & & 0.013 \\
\hline Calcium channel blocker (\%) & 10 & & 13.33 & & 20 & & 0.533 \\
\hline Insulin (\%) & - & & 13.33 & & 16.66 & & 0.718 \\
\hline Sulfonylurea (\%) & - & & 33.33 & & 43.33 & & 0.426 \\
\hline Glucophage (\%) & - & & 53.33 & & 56.66 & & 0.795 \\
\hline Thiazolidinedione (\%) & - & & 10 & & 13.33 & & 0.688 \\
\hline Duration of diabetes (years) & - & & 8.47 & \pm 5.46 & 12.17 & \pm 7.35 & $<0.001$ \\
\hline
\end{tabular}

Data are expressed as the mean with SD, median (inter-quartile range), or percentage. $P$-value for overall difference among the groups was calculated from the analysis of variance (ANOVA), the Kruskal-Wallis $\mathrm{H}$ test, or Pearson's chi-square test. BMI, body mass index; SBP, systolic blood pressure; DBP, diastolic blood pressure; HOMA-IR, homeostasis model assessment of insulin resistance; LDL, low-density lipoprotein; HDL, high-density lipoproteins; hsCRP, high sensitivity Creactive protein; IMT, intima-media thickness; baPWV, brachial ankle pulse wave velocity; ARB, angiotensin receptor blocker; $A C E$, angiotensin-converting enzyme inhibitor.

$\mathrm{a}, \mathrm{b}, \mathrm{c}$ : same letter indicates no statistical difference between the groups based on post hoc analysis.

of carotid plaque in subjects with type 2 diabetes, even after adjusting for confounding cardiovascular risk factors and detailed medication history.

\section{Adipokines and atherosclerosis}

The adipose tissues of individuals with type 2 diabetes secrete pro-inflammatory adipokines that contribute to the initiation of insulin resistance [24]. Some adipokines, such as resistin, leptin, and adiponectin directly mediate vascular health by influencing the function of endothelial cells, arterial smooth muscle cells, and macrophages in the vessel wall [3]. Recently, we reported that serum resistin and adipocyte fatty acid-binding protein are independently associated with atherosclerotic inflammation, as determined by $\left[{ }^{18} \mathrm{~F}\right]$-fluorodeoxyglucose positron emission tomography $[25,26]$. The production of adipokines by adipose tissue is an important mechanism for the adverse effects of adiposity on cardiovascular disease [27].

\section{Relationship of the novel adipokine omentin-1 with vascular health: Clinical studies}

Omentin, which is highly and selectively expressed in visceral adipose tissue, has been suggested to be an antiinflammatory molecule [28] and is thus assumed to have paracrine and autocrine roles in improving insulin sensitivity [7]. In 2011, several clinical studies examined the relationship between circulating omentin-1 with vascular health. Moreno-Navarrete et al. [11] demonstrated that the circulating omentin-1 concentration contributes independently to endothelial dysfunction even after controlling for adiposity, age, and inflammation in subjects with impaired glucose tolerance. In that study, vascular reactivity was measured by high-resolution ultrasound of the brachial artery. Since then, two other reports on the negative correlation of serum omentin-1 with carotid IMT have suggested an cardioprotective and anti-atherosclerotic role of omentin-1 [12,14]. Liu et al. [12] demonstrated that 


\section{Omentin-1 (ng/dL)}

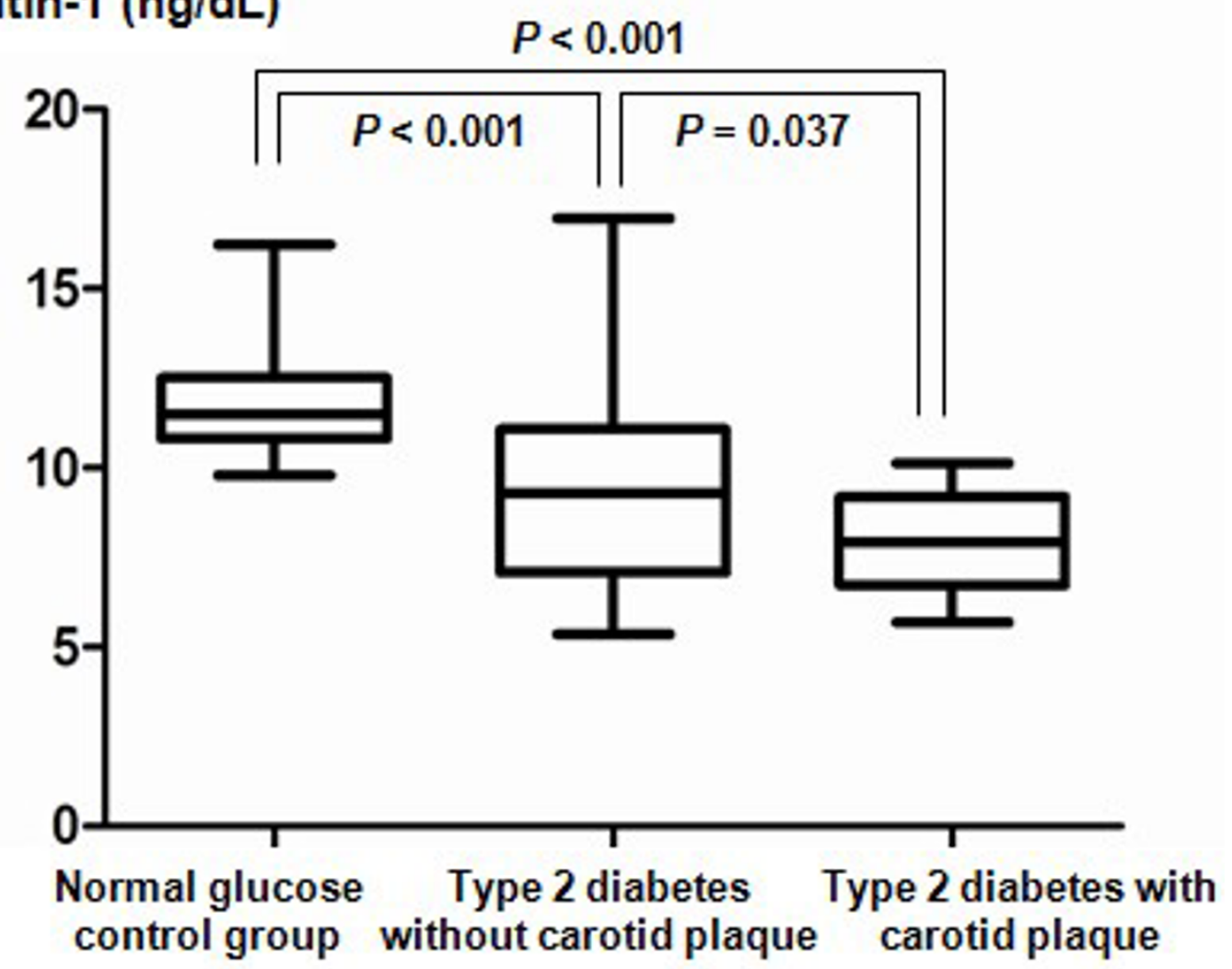

Figure 1 Serum omentin-1 levels in normal glucose tolerance group, type 2 diabetes patients without carotid plaque and type 2 diabetic patients with carotid plaque.

serum omentin-1 level was independently correlated with carotid IMT in metabolic syndrome patients and Shibata et al. [14] showed similar results in apparently healthy men. However, no studies have investigated the impact of serum omentin-1 level on atherosclerosis in type 2 diabetes. Recently, El-Mesallamy et al. [29] examined the circulating level of omentin-1 in an Egyptian population with type 2 diabetes, with and without ischemic heart disease. Although they did not detect clear differences in serum omentin-1 levels between type 2 diabetes patient with and without ischemic heart disease, multiple regression analysis showed that IL-6 level was an independent risk factor influencing serum omentin-1 level. This suggests that omentin-1 is regulated by inflammation. Inflammation is the most important factor linking type 2 diabetes to the progression of cardiovascular complication. Recently, Zhong et al. [13] demonstrated that serum omentin-1 levels were lower in patients with acute coronary syndrome or stable angina pectoris compared to controls. We showed that even after controlling for other risk factors and drug history that could affect vascular function, serum omentin-1 level was independently associated with arterial stiffness and carotid plaque. Previous studies and our results suggest that circulating omentin-1 might mediate not only the insulin signaling pathway but also directly affect the anti-atherosclerotic process.

Underlying mechanisms of omentin-1 and atherosclerosis: Experimental studies

Recently, several in vitro studies have been published that could explain the underlying mechanism of the connection between circulating omentin-1 and the atherosclerotic process. Yamawaki et al. [30] found that, in the isolated rat aorta, omentin directly induces an endothelium-dependent relaxation that is caused by nitric oxide produced by the endothelium. The same group [31] also showed that omentin inhibits TNF- $\alpha$ induced COX-2 expression by inhibiting the JNK signaling pathway in human umbilical vein endothelial cells, suggesting that omentin might prevent atherosclerosis by modulating the vascular endothelial inflammatory state. Furthermore, Xie et al. [32] reported that adenovirus-mediated overexpression of omentin- 1 attenuated arterial calcification in $\mathrm{OPG}^{-1-}$ mice, suggesting that increasing concentrations of omentin- 1 may be beneficial for protecting arteries. 


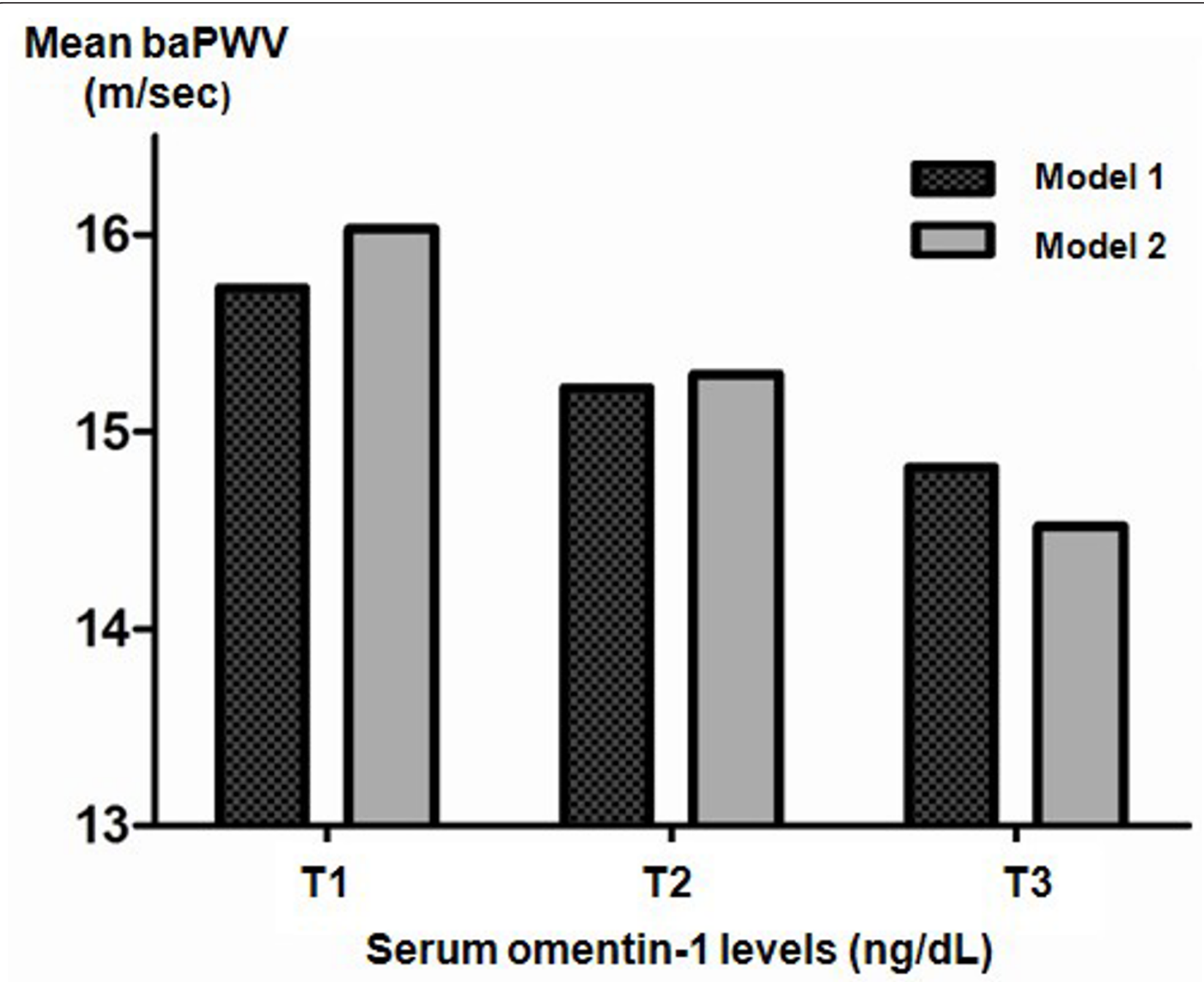

Figure 2 Mean values of brachial ankle pulse wave velocity (baPWV) based on the tertile of serum omentin-1 level in type 2 diabetes ( $\mathbf{N}=\mathbf{6 0})$. T1: lowest tertile of serum omentin-1, T2: median tertile of serum omentin-1, T3: highest tertile of serum omentin-1. Model 1: adjusted for age, gender and body mass index. Model 2: adjusted for age, gender, body mass index, systolic blood pressure, smoking and medication history including statins, angiotensin receptor blockers, or angiotensin-converting enzyme inhibitors.

\section{Limitations}

The principal limitation of our study was its crosssectional design. We cannot identify whether increased circulating omentin-1 had a direct impact on arterial stiffness and carotid plaque or was a consequence of increased arterial stiffness and arterial wall thickness. Therefore, we are planning a longitudinal study of the relationship of circulating omentin-1 levels with changes in baPWV and carotid plaque in people with newly diagnosed type 2 diabetes. Second, we enrolled only a limited sample, so the relationship between circulating omentin1 and atherosclerosis in type 2 diabetes should be further examined in a prospective design with a larger number of subjects. Lastly, although recent reports have demonstrated a close relationship between serum omentin and adiponectin levels, and that the regulation of omentin might be dependent on adiponectin [33], we did not measure adiponectin level. Further studies examining the influence of the relationship between omentin and adiponectin levels on cardiovascular disease would be interesting.

\section{Conclusions}

In conclusion, this study showed that the circulating omentin-1 level is significantly decreased in type 2 diabetes patients compared with control subjects and further decreased in subjects with carotid plaque. We demonstrated that serum omentin-1 level was independently associated with arterial stiffness and the presence of carotid plaque, even after adjusting for other cardiovascular risk factors and medication history. Additional experimental studies and large-scale prospective clinical studies are 
Table 2 Univariate and multivariate logistic regression analyses for carotid plaques in type 2 diabetes

\begin{tabular}{lllll}
\hline Variable & B & S.E & $\begin{array}{l}\text { Odds ratio } \\
(95 \% \text { C.I })\end{array}$ & P-value \\
\hline $\begin{array}{l}\text { Type 2 diabetes }(\mathrm{N}=60) \\
\text { Univariate }\end{array}$ & -0.369 & 0.156 & $0.692(0.510 \sim 0.938)$ & 0.018 \\
$\begin{array}{l}\text { Multivariate } \\
\quad \text { Model } 1^{*}\end{array}$ & -0.398 & 0.173 & $0.672(0.478 \sim 0.944)$ & 0.022 \\
$\quad$ Model 2 & -0.431 & 0.183 & $0.650(0.454 \sim 0.930)$ & 0.018 \\
$\quad$ Model $3^{\ddagger}$ & -0.432 & 0.201 & $0.649(0.438 \sim 0.962)$ & 0.031 \\
Model 4 $^{\S}$ & -0.476 & 0.200 & $0.621(0.420 \sim 0.919)$ & 0.017 \\
\hline
\end{tabular}

B, regression coefficient; S.E, standard error; C.I, confidence interval

* Adjusted for age and gender

${ }^{+}$Adjusted for age, gender and body mass index

‡ Adjusted for age, gender, body mass index, systolic blood pressure, fasting blood glucose and low density lipoprotein cholesterol

${ }^{5}$ Adjusted for age, gender, body mass index, systolic blood pressure, fasting blood glucose, low density lipoprotein cholesterol, smoking and medication history including anti-platelet agents and statins.

warranted to clarify the role of omentin-1 on the atherosclerotic process in people with type 2 diabetes.

\section{List of Abbreviations}

ARB: angiotensin receptor blocker; ACE: angiotensin-converting enzyme inhibitor; baPWV: brachial ankle pulse wave velocity; BMI: body mass index; DBP: diastolic blood pressure; IMT: intima-media thickness; HDL: high-density lipoproteins; HOMA-IR: homeostasis model assessment of insulin resistance; hsCRP: high sensitivity C-reactive protein; LDL: low-density lipoprotein; SBP: systolic blood pressure.

\section{Acknowledgements}

Dr. S.H. Baik was supported by a grant of the Korea Healthcare technology R\&D Project, Ministry of Health and Welfare, Republic of Korea (A102065) and a Korea University Grant (K1132331).

\section{Author details}

'Division of Endocrinology and Metabolism, Department of Internal Medicine, Korea University College of Medicine, Seoul, Korea. ${ }^{2}$ Department of Biostatistics, Korea University College of Medicine, Seoul, Korea.

\section{Authors' contributions}

HJY and SHB participated in the design of the study and performed the statistical analysis. HJY and SHB drafted the manuscript. HJY and SJY analysed the data. HCH, HYC, JAS, SGK, NHK, KMC and DSC conceived of the study, and participated in its design and coordination and helped to draft the manuscript. All authors read and approved the final manuscript.

\section{Competing interests}

The authors declare that they have no competing interests.

Received: 6 November 2011 Accepted: 22 November 2011 Published: 22 November 2011

\section{References}

1. Wild S, Roglic G, Green A, Sicree R, King H: Global prevalence of diabetes: estimates for the year 2000 and projections for 2030. Diabetes Care 2004, 27(5):1047-1053.

2. Almdal T, Scharling $H$, Jensen JS, Vestergaard $H$ : The independent effect of type 2 diabetes mellitus on ischemic heart disease, stroke, and death: a population-based study of 13,000 men and women with 20 years of follow-up. Arch Intern Med 2004, 164(13):1422-1426.

3. Fantuzzi G, Mazzone T: Adipose tissue and atherosclerosis: exploring the connection. Arterioscler Thromb Vasc Biol 2007, 27(5):996-1003.
4. Yang R, Xu A, Pray J, Hu H, Jadhao S, Hansen B, Shuldiner A, Mc-Lenithan J, Gong D: Cloning of omentin, a new adipocytokine from omental fat tissue in humans. Diabetes 2003, Suppl 1:A1.

5. Schaffler A, Neumeier M, Herfarth H, Furst A, Scholmerich J, Buchler C: Genomic structure of human omentin, a new adipocytokine expressed in omental adipose tissue. Biochim Biophys Acta 2005, 1732(1-3):96-102.

6. Xiang K, Wang Y, Zheng T, Jia W, Li J, Chen L, Shen K, Wu S, Lin X, Zhang $\mathrm{G}$, et al: Genome-wide search for type 2 diabetes/impaired glucose homeostasis susceptibility genes in the Chinese: significant linkage to chromosome 6q21-q23 and chromosome 1q21-q24. Diabetes 2004, 53(1):228-234.

7. Yang RZ, Lee MJ, Hu H, Pray J, Wu HB, Hansen BC, Shuldiner AR, Fried SK, McLenithan JC, Gong DW: Identification of omentin as a novel depotspecific adipokine in human adipose tissue: possible role in modulating insulin action. Am J Physiol Endocrinol Metab 2006, 290(6):E1253-1261.

8. Pan HY, Guo L, Li Q: Changes of serum omentin-1 levels in normal subjects and in patients with impaired glucose regulation and with newly diagnosed and untreated type 2 diabetes. Diabetes Res Clin Pract 2010, 88(1):29-33.

9. de Souza Batista CM, Yang RZ, Lee MJ, Glynn NM, Yu DZ, Pray J, Ndubuizu K, Patil S, Schwartz A, Kligman M, et al: Omentin plasma levels and gene expression are decreased in obesity. Diabetes 2007, 56(6):1655-1661

10. Tan BK, Adya R, Farhatullah S, Lewandowski KC, O'Hare P, Lehnert H, Randeva HS: Omentin-1, a novel adipokine, is decreased in overweight insulin-resistant women with polycystic ovary syndrome: ex vivo and in vivo regulation of omentin-1 by insulin and glucose. Diabetes 2008, 57(4):801-808.

11. Moreno-Navarrete JM, Ortega F, Castro A, Sabater M, Ricart W, FernandezReal JM: Circulating omentin as a novel biomarker of endothelial dysfunction. Obesity 2011, 19(8):1552-1559.

12. Liu R, Wang X, Bu P: Omentin-1 is associated with carotid atherosclerosis in patients with metabolic syndrome. Diabetes Res Clin Pract 2011, 93(1):21-25.

13. Zhong X, Zhang HY, Tan H, Zhou Y, Liu FL, Chen FQ, Shang DY: Association of serum omentin-1 levels with coronary artery disease. Acta Pharmacol Sin 2011, 32(7):873-878.

14. Shibata R, Takahashi R, Kataoka Y, Ohashi K, Ikeda N, Kihara S, Murohara T, Ouchi N: Association of a fat-derived plasma protein omentin with carotid artery intima-media thickness in apparently healthy men. Hypertens Res 2011.

15. Li Q, Yang Z, Lu B, Wen J, Ye Z, Chen L, He M, Tao X, Zhang W, Huang Y, et al: Serum uric acid level and its association with metabolic syndrome and carotid atherosclerosis in patients with type 2 diabetes. Cardiovasc Diabetol 2011, 10:72-79.

16. Shin JY, Lee HR, Lee DC: Increased arterial stiffness in healthy subjects with high-normal glucose levels and in subjects with pre-diabetes. Cardiovasc Diabetol 2011, 10:30-25.

17. Van de Veire NR, Djaberi R, Schuijf JD, Bax JJ: Non-invasive imaging: noninvasive assessment of coronary artery disease in diabetes. Heart 2010, 96(7):560-572.

18. Dalla Pozza R, Beyerlein A, Thilmany C, Weissenbacher C, Netz H, Schmidt $\mathrm{H}$, Bechtold S: The effect of cardiovascular risk factors on the longitudinal evolution of the carotid intima medial thickness in children with type 1 diabetes mellitus. Cardiovasc Diabetol 2011, 10:53-61.

19. Kubo T, Miyata M, Minagoe S, Setoyama S, Maruyama I, Tei C: A simple oscillometric technique for determining new indices of arterial distensibility. Hypertens Res 2002, 25(3):351-358.

20. American Diabetes Association: Standards of medical care in diabetes2010. Diabetes Care 2010, 33(Suppl 1):S11-61.

21. Friedewald WT, Levy RI, Fredrickson DS: Estimation of the concentration of low-density lipoprotein cholesterol in plasma, without use of the preparative ultracentrifuge. Clin Chem 1972, 18(6):499-502.

22. Yamashina A, Tomiyama $H$, Takeda $K$, Tsuda $H$, Arai T, Hirose $K$, Koji $Y$, Hori S, Yamamoto Y: Validity, reproducibility, and clinical significance of noninvasive brachial-ankle pulse wave velocity measurement. Hypertens Res 2002, 25(3):359-364.

23. Ebrahim S, Papacosta O, Whincup P, Wannamethee G, Walker M, Nicolaides AN, Dhanjil S, Griffin M, Belcaro G, Rumley A, et al: Carotid plaque, intima media thickness, cardiovascular risk factors, and 
prevalent cardiovascular disease in men and women: the British Regional Heart Study. Stroke 1999, 30(4):841-850.

24. DeFronzo RA: Insulin resistance, lipotoxicity, type 2 diabetes and atherosclerosis: the missing links. The Claude Bernard Lecture 2009. Diabetologia 2010, 53(7):1270-1287.

25. Yoo HJ, Kim S, Park MS, Choi HY, Yang SJ, Seo JA, Kim SG, Kim NH, Baik SH, Choi DS, et al: Serum adipocyte fatty acid-binding protein is associated independently with vascular inflammation: analysis with (18)Ffluorodeoxyglucose positron emission tomography. J Clin Endocrinol Metab 2011, 96(3):E488-492.

26. Choi HY, Kim S, Yang SJ, Yoo HJ, Seo JA, Kim SG, Kim NH, Baik SH, Choi DS, Choi KM: Association of adiponectin, resistin, and vascular inflammation: analysis with 18F-fluorodeoxyglucose positron emission tomography. Arterioscler Thromb Vasc Biol 2011, 31(4):944-949.

27. Yu YH, Ginsberg HN: Adipocyte signaling and lipid homeostasis: sequelae of insulin-resistant adipose tissue. Circ Res 2005, 96(10):1042-1052.

28. Tan BK, Adya R, Randeva HS: Omentin: a novel link between inflammation, diabesity, and cardiovascular disease. Trends Cardiovasc Med 2010, 20(5):143-148.

29. El-Mesallamy HO, El-Derany MO, Hamdy NM: Serum omentin-1 and chemerin levels are interrelated in patients with Type 2 diabetes mellitus with or without ischaemic heart disease. Diabet Med 2011, 28(10):1194-1200.

30. Yamawaki H, Tsubaki N, Mukohda M, Okada M, Hara Y: Omentin, a novel adipokine, induces vasodilation in rat isolated blood vessels. Biochem Biophys Res Commun 2010, 393(4):668-672.

31. Yamawaki H, Kuramoto J, Kameshima S, Usui T, Okada M, Hara Y: Omentin, a novel adipocytokine inhibits TNF-induced vascular inflammation in human endothelial cells. Biochem Biophys Res Commun 2011, 408(2):339-343.

32. Xie $H$, Xie PL, Wu XP, Chen $S M$, Zhou HD, Yuan LQ, Sheng ZF, Tang SY, Luo XH, Liao EY: Omentin-1 attenuates arterial calcification and bone loss in osteoprotegerin-deficient mice by inhibition of RANKL expression. Cardiovasc Res 2011.

33. Yan $\mathrm{P}$, Liu D, Long M, Ren Y, Pang J, Li R: Changes of serum omentin levels and relationship between omentin and adiponectin concentrations in type 2 diabetes mellitus. Exp Clin Endocrinol Diabetes 2011, 119(4):257-263.

doi:10.1186/1475-2840-10-103

Cite this article as: Yoo et al: Association of circulating omentin-1 level with arterial stiffness and carotid plaque in type 2 diabetes.

Cardiovascular Diabetology 2011 10:103.

\section{Submit your next manuscript to BioMed Central and take full advantage of:}

- Convenient online submission

- Thorough peer review

- No space constraints or color figure charges

- Immediate publication on acceptance

- Inclusion in PubMed, CAS, Scopus and Google Scholar

- Research which is freely available for redistribution

Submit your manuscript at www.biomedcentral.com/submit
CioMed Central 